\title{
ROLE OF ULTRASOUND AND TRANSIENT ELASTOGRAPHY IN DIAGNOSIS OF OCCULT CIRRHOSIS IN CHRONIC LIVER DISEASE
}

\author{
Mohamed Fikry Mohamed Ali, Abdallah Mohamed El Kheshen and \\ Mohamad Abo Al Naga
}

\author{
Department of Radiodiagnosis, Faculty of Medicine, Al-Azhar University \\ Corresponding author: Mohamed Fikry Mohamed Ali, E-Mail: \\ mohamedmohamedali88@gmail.com
}

\begin{abstract}
Background: Hepatic cirrhosis represents the most advanced stage of any chronic liver disease characterized by progressive fibrosis. Complications including decompensation, spontaneous bacterial peritonitis, variceal bleeding, and hepatocellular carcinoma, carry significant morbidity and mortality. Early identification of patients with cirrhosis is of paramount importance to initiate surveillance protocols for prevention, early diagnosis, and specific therapies for such devastating complications.

Objective: To investigate prevalence of preclinical cirrhosis diagnosed by transient elastography (TE) that we defined as occult cirrhosis (OC) and to evaluate the pattern of surveillance that patients with OC received in current clinical practice.

Patients and methods: Our study included 60 chronic liver disease patients recruited from National Hepatology and Tropical Medicine Research Institute (NHTMRI) outpatient clinics to assess prevalence of occult cirrhosis among patients who have not any clinical or definite sonographic signs of liver cirrhosis, the study was divided into two groups: 1) Occult cirrhosis, defined as TE $\geq 13 \mathrm{kPa}$ and F4 on METAVIR scoring system. 2) non-cirrhotic chronic liver disease (CLD) (TE $<13 \mathrm{kPa})$. We found that the prevalence of $\mathrm{OC}$ is considerable, representing $15 \%$ of all CLD patients. This proportion suggests up to 1 in 7 individuals with CLD may have their OC missed.

Results: Concerning the etiology of the chronic liver disease in our study, among the occult cirrhosis group there were 8 patients diagnosed as hepatitis $\mathrm{C}$ virus positive representing $(89 \%)$ and one patient diagnosed as hepatitis B virus positive representing $(11 \%)$ and among the non-cirrhotic group there were 42 patients diagnosed as hepatitis $\mathrm{C}$ virus positive representing (82\%) and 4 patients diagnosed as hepatitis B virus positive representing (8\%) and 5 patients diagnosed as nonalcoholic fatty liver disease (NAFLD) representing (10\%). In our study among the occult cirrhosis group there were 5 male patients $(55 \%)$ and 4 females $(45 \%)$ with their age ranged between $33-55$ years with the mean age 44 years and among the
\end{abstract}


non-cirrhotic group there were 32 male patients $(62.7 \%)$ and 19 female patients (37.3\%) their age ranged between 19-58 years with the mean age 38.5 years.

Conclusion: This study suggests that occult cirrhosis is a frequent finding. Clinicians should be aware that the absence of definite sonographic signs cannot rule out the possibility of compensated cirrhosis in its preclinical stage. Patients with occult cirrhosis can exhibit rapid development of hepatocellular carcinoma, variceal bleeding, and ascites.

Keywords: Chronic liver disease, Occult cirrhosis, Transient elastography

\section{INTRODUCTION}

Occult cirrhosis is a frequent clinical entity that is likely under-diagnosed, with significant risk for rapid development of hepatic decompensation. These patients are more likely to be misclassified and receive the same monitoring schedule as non-cirrhotic patients, potentially delaying essential treatments or late detection of a treatable complication as hepatocellular carcinoma (HCC) or esophageal varices (Tianyan et al., 2015).

Patients with cirrhosis due to chronic hepatitis $\mathrm{C}$ would benefit the most from new generation, interferon free antiviral regimens, which can potentially delay or prevent decompensation (D'Amico et al., 2014).

Unfortunately, in $20-63 \%$ of cirrhotic patients, the diagnosis is only made upon first presentation of its endstage complications, which continue to accumulate, recur more frequently and ultimately shorten life expectancy (Durand and Valla, 2010).

Until recently, the description of a liver as "cirrhotic", often by clinical, radiologic or laboratory findings, was sufficient to define a patient's prognosis. Garcia-Tsao et al. suggested that cirrhosis is a dynamic condition encompassing a more complex clinicopathological spectrum (Garcia Tsao et al., 2010).
Decompensated disease is defined by clinically evident complications from portal hypertension, hepatic encephalopathy, or jaundice. Although some patients with compensated cirrhosis may have signs that will alert clinicians towards such diagnosis (i.e. thrombocytopenia, ultrasonographic findings, or esophageal varices), many patients do not. These patients at the preclinical stage of compensated cirrhosis represent a major diagnostic challenge for clinicians, and often remain undiagnosed and receive suboptimal surveillance for portal hypertension complications or HCC (Garcia-Tsao et al., 2010 and de Franchis, 2010).

Liver biopsy has long been considered the gold standard for the diagnosis of hepatic cirrhosis, particularly when clinical signs are absent. However, the morbidity, cost, and potential underestimation of fibrosis stage due to sampling errors have necessitated the development of non-invasive methods (Sebastiani et al., 2012).

The measurement of liver stiffness by transient elastography (TE, Fibroscan; Echosens, France) is a validated technique which showed high accuracy in predicting cirrhosis. The performance of TE as expressed as area under the curve (AUC) ranges from 0.90 to 0.99 for the diagnosis of cirrhosis (Castera, 2012). 


\section{ROLE OF ULTRASOUND AND TRANSIENT ELASTOGRAPHY ...}

Serum biomarkers based on simple parameters, such as aspartate aminotransferase/platelet ratio index (APRI) and FIB-4 based on age, platelets and transaminases, have also been proposed. However, TE outperforms these biomarkers in the diagnosis of cirrhosis (Degos et al., 2010).
Intrahepatic vessels may be indistinct. Unfortunately, these signs are both insensitive and insufficiently specific for cirrhosis to be diagnosed reliably. Nevertheless, evaluation of the smoothness or nodularity liver surface with a highresolution linear array transducer is

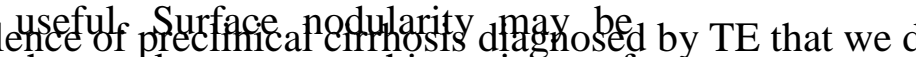
the only sonographic sign of cirrhosis. However (Gerstenmaier et al., 2014) found that liver parenchymal texture has a statistically significant correlation with the degree of fibrosis. When combined with two more features (liver surface nodularity and liver edge), has better accuracy for the presence of cirrhosis. Other signs of cirrhosis such as small liver size hypertrophy of caudate lobe, splenomegaly, or ascites.

6. Doppler signs of portal hypertension as enlarged portal vein $>14 \mathrm{~mm}$, slow portal venous flow $<15 \mathrm{~cm} / \mathrm{sec}$, reversal of portal venous flow (hepatofugal), portal vein thrombosis, portosystemic collaterals, portalization of the hepatic veins waveform, corkscrew appearance of the hepatic artery

7. Failure of Transient elastography examination as defined as no validated measure obtained by the machine.

8. Unreliable TE defined as $<10$ validated measures and/or interquartile range (IQR) $>30 \%$ and/or a success rate of less than $60 \%$ (ratio of the number of successful acquisitions over the total number of acquisitions). IQR was defined as an index of intrinsic variability of LSM corresponding to the interval of LSM results containing $50 \%$ of the valid 
measurements between the 25th and 75 th percentiles. The median value was considered representative of the elastic modulus of the liver. Only LSMs with at least $10 \mathrm{VMs}$ were considered reliable. Any LSM that did not meet these criteria of reliability was excluded.

9. Risk factors for false positivity of TE, including cardiac insufficiency, ALT flares, extrahepatic cholestasis.

10.Severe co-morbidities exceeding complaints.

\section{Cognitive or sensory motor problems.}

\section{All patients were subjected to the following:}

1. Full history taking and clinical examination.

2. Body mass index (BMI) was calculated for all patients.

3. Routine laboratory investigations were estimated including complete blood count, liver function assessment, serum alanine aminotransferase, serum aspartate aminotransferase, total and direct bilirubin, serum albumin, and prothrombin time and concentration with INR.

4. Aetiology of liver disease investigations included, HBs- Ag, $\mathrm{HCV}-\mathrm{Ab}$, and HCV- PCR.

5. The following simple biomarkers for liver fibrosis were calculated: APRI defined as: [100 x (AST/upper limit of normality)/platelet count]; APRI $>2$ to diagnose cirrhosis. FIB-4 calculated as: age (years) $\times$ AST /platelet count $\times$ ALT $1 / 2$. The following cutoff values indicated in the original publications were applied: FIB-4 $>3.25$ to diagnose advanced fibrosis (Vallet-Pichard et al., 2011).

6. Conventional abdominal ultrasonography was performed by the same radiologist using a $3.5 \mathrm{MHz}$ curvilinear transducer of Toshiba Aplio 400 ultrasound machine to assess the liver size, texture, focal lesions, portal vein diameter and patency, splenic size, texture and to assess the presence or absence of ascites.

7. Liver stiffness measurement using the transient elastography (Fibroscan).

It was performed using the Fibroscan device (Echosens, Paris, France) loca7ted at the NHTMRI. This consists of $5 \mathrm{MHz}$ ultrasound transducer probe mounted on the axis of a vibrator.

Vibrations of mild amplitude and low frequency are transmitted by the transducer, inducing an elastic shear wave that propagates through the underlying tissues.

Velocity is directly related to tissue stiffness the stiffer the tissue, the faster the shear wave propagates.

- The patient was lying in the dorsal decubitus with the right arm in maximal abduction. The tip of the transducer was covered with a drop of gel and measurements were performed in the right lobe of the liver by placing the tip of the transducer perpendicularly in the intercostal space.

- Under the control of TM and Amode, the operator located a liver portion at least $6 \mathrm{~cm}$ thick and free of large vascular structures. Stiffness is measured on a cylinder of hepatic tissue of $1 \mathrm{~cm}$ diameter and 2 to $4 \mathrm{~cm}$ 
of length.

- The median value of ten successful acquisitions expressed in kilopascal (kpa) and was kept as representative of liver stiffness measurement.

- The clinical interpretation of TE depends on two important parameters for results to be considered reliable:

1. The interquartile range, which reflects the variability of the validated measures, should not exceed $30 \%$ of the median value.

2. The success rate (the ratio of the number of successful measurements to the total number of acquisitions) should be at least $60 \%$.

3. Cirrhosis was diagnosed when the liver stiffness was $>13 \mathrm{kPa}$. This threshold has been demonstrated to be the optimal cut-off for cirrhosis in a meta-analysis and in a study performed in the general population

(Roulot et al., 2011).

Statistical analysis: Data collected throughout history, basic clinical examination, laboratory investigations and outcome measures coded, entered and analyzed using Microsoft Excel software. Data were then imported into Statistical Package for the Social Sciences (SPSS version 20.0) (Statistical Package for the Social Sciences) software for analysis. According to the type of data qualitative represent as number and percentage, quantitative continues group represent by mean $\pm \mathrm{SD}$, the following tests were used to test differences for significance difference and association of qualitative variable by Chi square test $\left(\mathrm{X}^{2}\right)$. Differences between quantitative multiple by ANOVA or Kruskal Wallis. $\mathrm{P}$ value was set at $<0.05$ for significant results \& $<0.001$ for high significant result. 


\section{Case 1:}

Clinical history: 56 years old $\mathrm{HCV}+\mathrm{ve}$ female patient.

Laboratory investigations:

Platelet=339000/cmm , PC= 77\%, INR= 1.1, ALT= 65, AST= 41, S. Albumin 5 g/dl, S.Bilirubin $1.2 \mathrm{mg} / \mathrm{dl}$

Biomarkers for liver fibrosis: $A P R I=0.302, F I B-4=0.84$

US findings: Average hepatic size, coarse echo-texture, smooth hepatic, no periportal thickening with average splenic size.

Doppler findings: Patent PV with average diameter and hepatopetal flow.

Fibroscan Reading: $8.3 \mathrm{KPa}$

Fibroscan Score: F2

Histopatholgical score: A1, F2
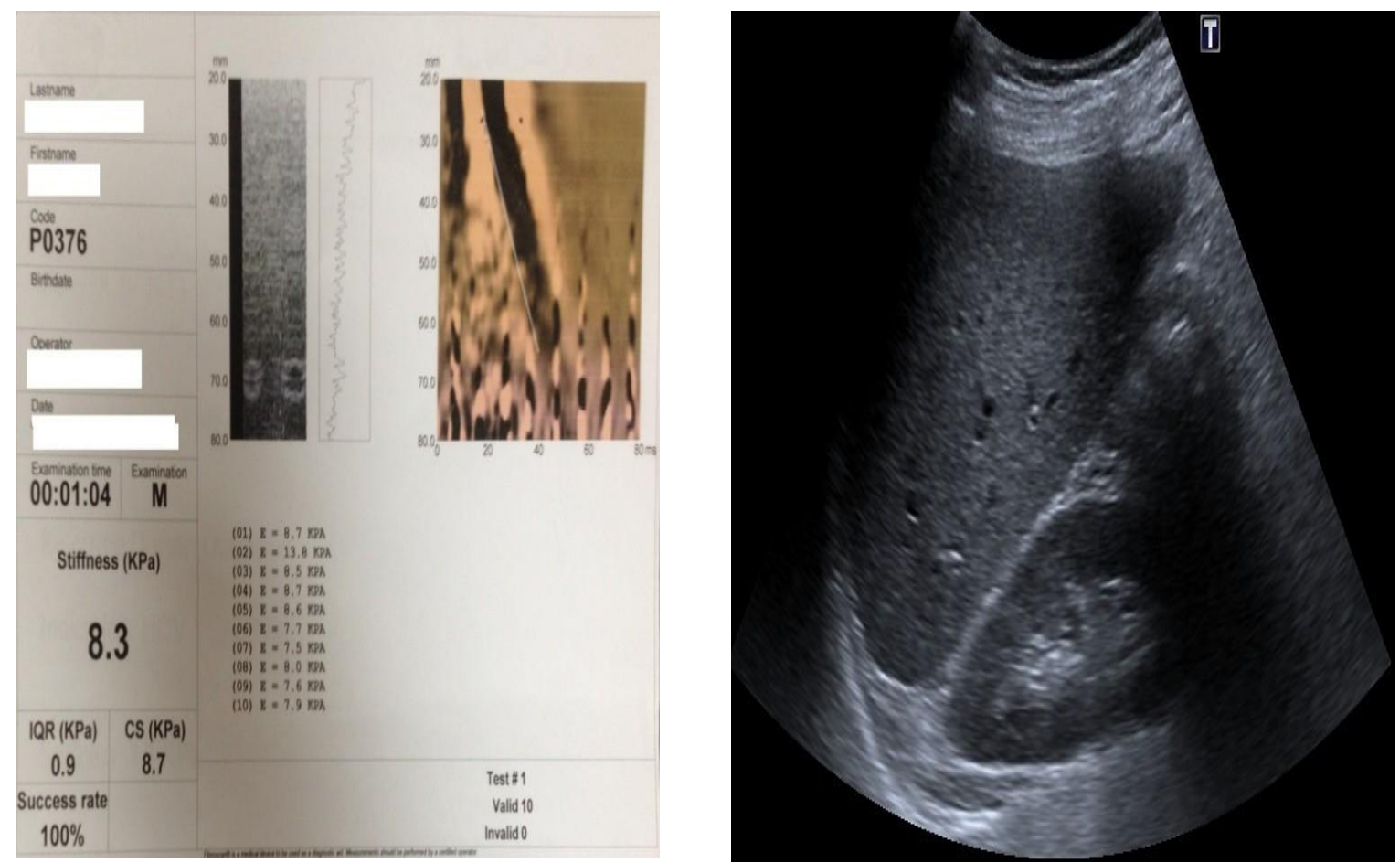
ROLE OF ULTRASOUND AND TRANSIENT ELASTOGRAPHY ...

\section{Case 2:}

Clinical history: 33 years old HCV +ve female patient.

Laboratory investigations:

Platelet $=153000 / \mathrm{cmm}, \mathrm{PC}=88 \%, \mathrm{INR}=1.1, \mathrm{ALT}=31, \mathrm{AST}=25, \mathrm{~S}$. Albumin $4.6 \mathrm{~g} / \mathrm{dl}$, S.Bilirubin $0.9 \mathrm{mg} / \mathrm{dl}$

Biomarkers for liver fibrosis: $\mathrm{APRI}=0.454, \mathrm{FIB}-4=0.97$

US findings: average hepatic size, coarse echo-texture, smooth hepatic surface, no periportal thickening with average splenic size.

Doppler findings: Patent PV with average diameter and hepatopetal flow.

Fibroscan Reading: $19.8 \mathrm{KPa}$

Fibroscan Score: F4

Histopatholgical score: A1, F4
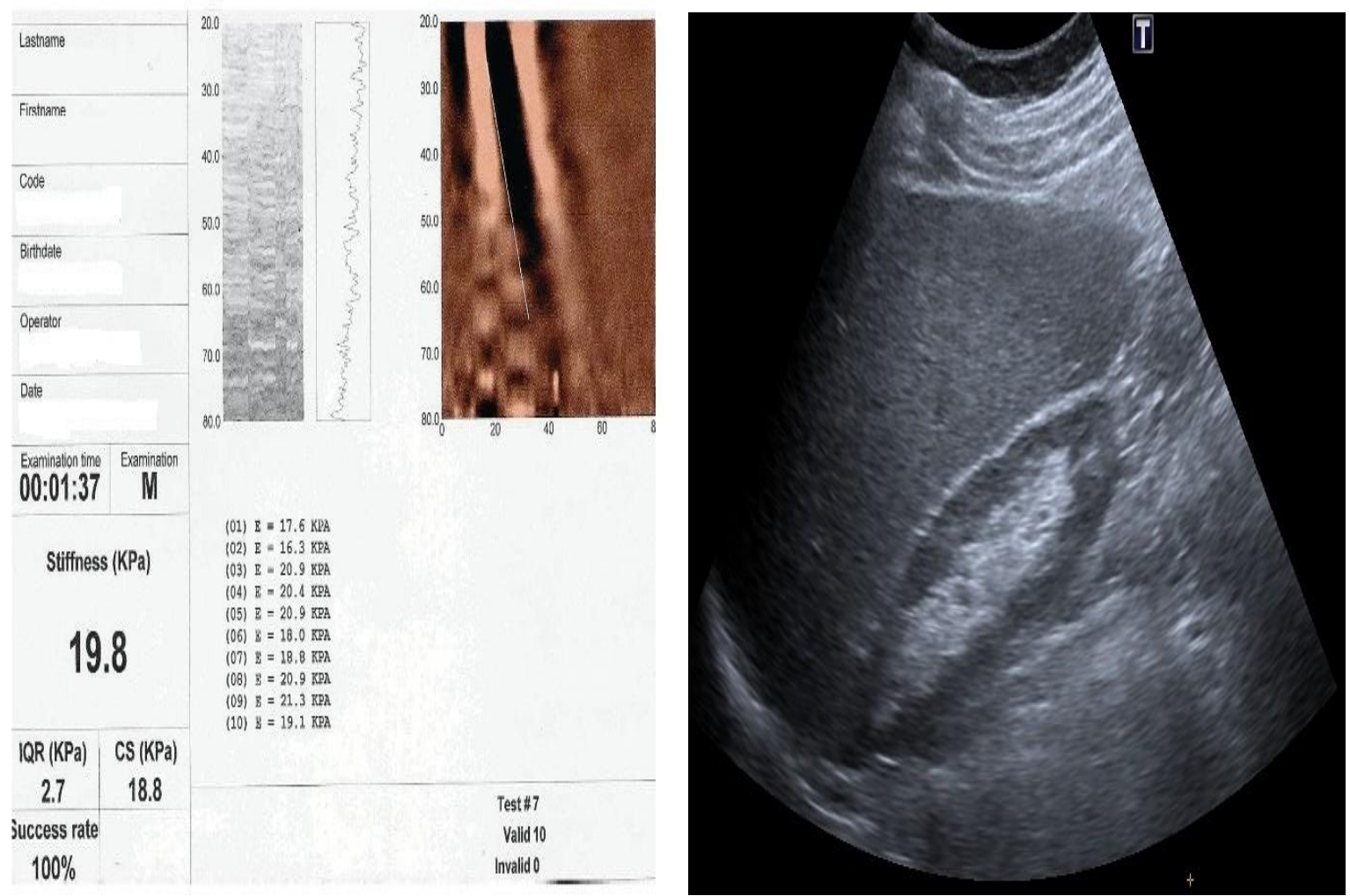


\section{RESULTS}

This study was applied on 60 chronic liver diseases patients, recruited from outpatient clinics of NHTMRI and the following are the results after statistical analysis of their clinical data, lab investigations, abdominal US and Fibroscan scores.

In our study among the occult cirrhosis group there were 5 male patients $(55 \%)$ and 4 females $(45 \%)$ with their age ranged between 33-55 years with the mean age
44 years and among the non-cirrhotic group there were 32 male patients $(62.7 \%)$ and 19 female patients $(37.3 \%)$ their age ranged between $19-58$ years with the mean age 38.5 years.

Concerning the BMI in our study, among the occult cirrhosis group BMI was ranging from 25 to 33.7 (29.3) and among non-cirrhotic group the BMI was ranging from 18.9 to 35.2 (27.05) (Table 1).

Table (1): Characteristics age, sex and etiology of chronic liver disease of the studied population.

\begin{tabular}{|c|c|c|c|c|c|c|}
\hline & NO & Mean & $\begin{array}{c}\text { Study } \\
\text { Deviation }\end{array}$ & Median & Minimum & Maximum \\
\hline Age & 60 & 41.867 & 9.5109 & 41.000 & 19.0 & 58.0 \\
\hline $\begin{array}{c}\text { BM } \\
\text { I }\end{array}$ & 60 & 28.448 & 3.6780 & 28.950 & 18.9 & 35.2 \\
\hline & & & \multicolumn{2}{|c|}{ NO. } & \multicolumn{2}{|c|}{$\%$} \\
\hline \multicolumn{3}{|c|}{ Females } & \multicolumn{2}{|c|}{23} & \multicolumn{2}{|c|}{$38.3 \%$} \\
\hline \multicolumn{3}{|c|}{ Males } & \multicolumn{2}{|c|}{37} & \multicolumn{2}{|c|}{$61.7 \%$} \\
\hline \multicolumn{3}{|c|}{ HCV } & \multicolumn{2}{|c|}{50} & \multicolumn{2}{|c|}{$83.3 \%$} \\
\hline \multicolumn{3}{|c|}{ HBV } & \multicolumn{2}{|c|}{5} & \multicolumn{2}{|c|}{$8.3 \%$} \\
\hline \multicolumn{3}{|c|}{ NAFLD } & \multicolumn{2}{|c|}{5} & \multicolumn{2}{|c|}{$8.3 \%$} \\
\hline
\end{tabular}

Concerning the etiology of the chronic liver disease in our study, among the occult cirrhosis group there were 8 patients diagnosed as $\mathrm{HCV}$ positive representing $(89 \%)$ and one patient diagnosed as HBV positive representing
(11\%) and among the non-cirrhotic group there were 42 patients diagnosed as $\mathrm{HCV}$ positive representing (82\%) and 4 patients diagnosed as HBV positive representing $(8 \%)$ and 5 patients diagnosed as NAFLD representing (10\%) (Table 2).

Table (2): Relation of Sex and etiology of CLDS to occult cirrhosis.

\begin{tabular}{|l|l|c|c|c|c|c|c|}
\hline \multicolumn{2}{|c|}{} & \multicolumn{2}{c|}{ Non-Cirrhotic } & \multicolumn{2}{c|}{ Occult Cirrhosis } & \multirow{2}{*}{ Total } & \multirow{2}{*}{$\begin{array}{c}\text { P- } \\
\text { value }\end{array}$} \\
\cline { 3 - 6 } \multicolumn{2}{|c}{ Sex } & No & No & No & $\%$ & & \multirow{2}{*}{0.72} \\
& Male & 19 & $37 \%$ & 4 & $44 \%$ & 23 & \\
\hline HCV & & 42 & $63 \%$ & 5 & $55 \%$ & 37 & \\
\hline HBV & 4 & $82 \%$ & 8 & $89 \%$ & 50 & 1.0 \\
\hline NAFLD & 5 & $10 \%$ & 1 & $11 \%$ & 5 & 0.57 \\
\hline
\end{tabular}


Total bilirubin was ranging from 0.5 to $1.9 \mathrm{mg} / \mathrm{dl}(1.2 \mathrm{mg} / \mathrm{dl})$, AST level was ranging from 25 to $180 \mathrm{U} / \mathrm{L}(102.5 \mathrm{U} / \mathrm{L})$, ALT level was ranging from 18 to 231 $\mathrm{U} / \mathrm{L}$ (124.5 U/L) ,serum albumin level was ranging from 3.4 to $4.6 \mathrm{~g} / \mathrm{dl}(4 \mathrm{~g} / \mathrm{dl})$, prothrombin concentration was ranging from 65 to $96 \%(80.5 \%)$ and INR ranging from 1 to 1.4 (1.2), mean of serum $\mathrm{HB}$ was ranging from 12.2 to $17.7 \mathrm{~g} / \mathrm{dl}(14.9$ $\mathrm{g} / \mathrm{dl}$ ) and platelets was ranging from 150000 to $266000 / \mathrm{L}$ (208000/L), and among the non-cirrhotic group: total bilirubin was ranging from 0.3 to 1.9 $\mathrm{mg} / \mathrm{dl}(1.1 \mathrm{mg} / \mathrm{dl})$, AST level was ranging from 11 to $150 \mathrm{U} / \mathrm{L}$ (80.5 U/L), ALT level was ranging from 4 to $243 \mathrm{U} / \mathrm{L}$ (123.5
U/L) ,serum albumin level was ranging from 3.2 to $5.2 \mathrm{~g} / \mathrm{dl}(4.2 \mathrm{~g} / \mathrm{dl})$, prothrombin concentration was ranging from 73 to $100 \%(86.5 \%)$ and INR ranging from 0.9 to 1.4 (1.15), serum $\mathrm{HB}$ was ranging from 12.2 to $16.8 \mathrm{~g} / \mathrm{dl}(14.5$ $\mathrm{g} / \mathrm{dl}$ ) and platelets was ranging from 150000 to $419000 / \mathrm{L}(284000 / \mathrm{L})$.

Concerning the liver fibrosis biomarkers, among the occult cirrhosis group the APRI score was ranging from 0.423 to 3.041 (1.73) and FIB-4 score was ranging from 0.97 to 3.76 (2.37), and among the non-cirrhotic group the APRI score was ranging from 0.08 to 2.679 (1.38) and FIB-4 score was ranging from 0.41 to 2.78 (1.595) (Table 3 ).

Table (3): Relation of investigation results, liver fibrosis biomarkers, fibroscan score to Occult cirrhosis.

\begin{tabular}{|l|c|c|c|c|c|c|c|}
\hline & \multicolumn{3}{|c|}{ Non-Cirrhotic } & \multicolumn{3}{c|}{ Occult Cirrhosis } & P \\
\cline { 2 - 7 } & $\begin{array}{c}\text { Media } \\
\mathbf{n}\end{array}$ & $\begin{array}{c}\text { Minim } \\
\text { um }\end{array}$ & $\begin{array}{c}\text { Maxim } \\
\text { um }\end{array}$ & $\begin{array}{c}\text { Media } \\
\mathbf{n}\end{array}$ & $\begin{array}{c}\text { Minim } \\
\text { um }\end{array}$ & $\begin{array}{c}\text { Maxim } \\
\text { um }\end{array}$ & \\
\hline $\begin{array}{l}\text { T.BILRUBI } \\
\text { N }\end{array}$ & 1.1 & 0.3 & 1.9 & 1.2 & 0.5 & 1.9 & 0.129 \\
\hline $\begin{array}{l}\text { S. } \\
\text { ALBUMIN }\end{array}$ & 4.2 & 3.2 & 5.2 & 4 & 3.4 & 4.6 & 0.198 \\
\hline AST & 80.5 & 11 & 150 & 102.5 & 25 & 180 & 0.065 \\
\hline ALT & 123.5 & 4 & 243 & 124.5 & 18 & 231 & 0.207 \\
\hline PLAT & 284000 & 150000 & 419000 & 208000 & 150000 & 266000 & 0.003 \\
\hline PC & $86.5 \%$ & $73 \%$ & $100 \%$ & 80.5 & 65 & 96 & 0.003 \\
\hline INR & 1.15 & 0.9 & 1.4 & 1.2 & 1 & 1.4 & 0.007 \\
\hline APRI & 0.47 & 0.08 & 2.68 & 1.11 & 0.42 & 3.04 & 0.004 \\
\hline FIB-4 & 0.91 & 0.41 & 84.00 & 1.98 & 0.97 & 3.76 & 0.007 \\
\hline $\begin{array}{l}\text { fibroscan } \\
\text { Score }\end{array}$ & 9.45 & 3.20 & 15.7 & 15.30 & 7.80 & 27.00 & 0.001 \\
\hline
\end{tabular}

Concerning the US finding of the liver, among the occult cirrhosis group, there were 7 patients with average liver size $(78 \%)$ and 2 patients with enlarged liver size (22\%), there were 4 patients with bright echotexture $(45 \%)$ and 5 patients with coarse echotexture (55\%), and among the non-cirrhotic group there 
were 20 patients with average liver size $(39 \%)$ and 31 patients with enlarged liver size $(61 \%)$, there were 30 patients with bright echotexture $(59 \%)$ and 21 patients with coarse echotexture (41\%) (Table 4).

Table (4): Relation Liver size and texture by Ultrasound to occult cirrhosis.

\begin{tabular}{|c|c|c|c|c|c|c|}
\hline & \multicolumn{2}{|c|}{ Non-Cirrhotic } & \multicolumn{2}{|c|}{ Occult Cirrhosis } & \multirow[b]{2}{*}{ P value } \\
\hline & & No & $\%$ & No & $\%$ & \\
\hline \multirow[t]{2}{*}{ Size } & Average & 20 & $39 \%$ & 7 & $78 \%$ & \multirow{2}{*}{0.07} \\
\hline & Enlarged & 31 & $61 \%$ & 2 & $22 \%$ & \\
\hline \multirow[t]{2}{*}{ Texture } & Bright & 30 & $59 \%$ & 4 & $45 \%$ & \multirow[b]{2}{*}{0.48} \\
\hline & Coarse & 21 & $41 \%$ & 5 & $55 \%$ & \\
\hline
\end{tabular}

Liver size detected by US: In fibroscan score F0 there were 12 patients $(70 \%)$ average size and 5 patients $(29.5 \%)$ enlarged size, F1 there were 2 patients (70\%) average size and 5 patients $(29.5 \%)$ enlarged size, F2 there were 4 patients (45\%) average size and 5 patients $(55 \%)$ enlarged size, F3 there were 4 patients $(57 \%)$ average size and 3 patients $(43 \%)$ enlarged size, F4 there was 1 patient $(10 \%)$ average size and 9 patients $(90 \%)$ enlarged size.
Liver echotexture detected by US: In fibroscan score F0 there were 13 patients (76.5\%) bright echotexture and 4 patients $(23.5 \%)$ coarse echotexture, F1 there were 11 patients $(65 \%)$ bright echotexture and 6 patients $(35 \%)$ coarse echotexture, F2 there were 3 patients $(33.3 \%)$ bright echotexture and 6 patients $(66.6 \%)$ coarse echotexture, F3 there were 3 patients $(43 \%)$ bright echotexture and 4 patients $(57 \%)$ coarse echotexture, F4 there were 4 patients $(40 \%)$ bright echotexture and 6 patients $(60 \%)$ coarse echotexture (Table 5). 
ROLE OF ULTRASOUND AND TRANSIENT ELASTOGRAPHY ...

Table (5): Relation between hepatic size (MCL) and hepatic echotexture to fibroscan.

\begin{tabular}{|c|c|c|c|c|c|c|c|}
\hline \multirow[b]{2}{*}{ Size } & \multicolumn{5}{|c|}{ Fibrosis by Fibroscan } & \multirow[b]{2}{*}{ Total } & \multirow[b]{2}{*}{ P value } \\
\hline & FO & $\begin{array}{l}F \\
1 \\
\end{array}$ & $\mathbf{F 2}$ & $\begin{array}{l}\mathbf{F} \\
3\end{array}$ & $\begin{array}{l}F \\
4 \\
\end{array}$ & & \\
\hline Average & $\begin{array}{c}12 \\
70.5 \% \\
\end{array}$ & $\begin{array}{c}12 \\
70.5 \% \\
\end{array}$ & $\begin{array}{c}4 \\
45.0 \% \\
\end{array}$ & $\begin{array}{c}4 \\
57.0 \% \\
\end{array}$ & $\begin{array}{c}1 \\
10.0 \% \\
\end{array}$ & $\begin{array}{c}33 \\
55.0 \% \\
\end{array}$ & \\
\hline Enlarged & $\begin{array}{c}5 \\
29.5 \% \\
\end{array}$ & $\begin{array}{c}5 \\
29.5 \% \\
\end{array}$ & $\begin{array}{c}5 \\
55.0 \% \\
\end{array}$ & $\begin{array}{c}3 \\
43.0 \% \\
\end{array}$ & $\begin{array}{c}9 \\
90.0 \% \\
\end{array}$ & $\begin{array}{c}27 \\
45.0 \% \\
\end{array}$ & 0.02 \\
\hline Bright & $\begin{array}{c}13 \\
76.5 \% \\
\end{array}$ & $\begin{array}{c}11 \\
64.7 \% \\
\end{array}$ & $\begin{array}{c}3 \\
33.3 \% \\
\end{array}$ & $\begin{array}{c}3 \\
42.0 \% \\
\end{array}$ & $\begin{array}{c}4 \\
40 \% \\
\end{array}$ & $\begin{array}{c}34 \\
56.6 \% \\
\end{array}$ & 0.17 \\
\hline Coarse & $\begin{array}{c}4 \\
23.5 \% \\
\end{array}$ & $\begin{array}{c}6 \\
35.3 \% \\
\end{array}$ & $\begin{array}{c}6 \\
66.6 \% \\
\end{array}$ & $\begin{array}{c}4 \\
57.0 \% \\
\end{array}$ & $\begin{array}{c}6 \\
60 \% \\
\end{array}$ & $\begin{array}{c}26 \\
43.3 \% \\
\end{array}$ & \\
\hline
\end{tabular}

Sensitivity of TE $>10$ is: $88.9 \%$, Specificity $84.3 \%$, negative predictive value is $=97.7 \%$, positive predictive value $=50 \%$. Sensitivity of TE $>13$ is: $66.7 \%$, Specificity $92.2 \%$, negative predictive value is $=94 \%$, positive predictive value $=40 \%$.

Table (6): Sensitivity of Transient Elastography to detect cirrhosis if score $>10$ and $>13 \mathrm{KPa}$.

\begin{tabular}{|c|c|c|c|c|c|}
\hline & & & $\begin{array}{c}\text { Non } \\
\text { Cirrhotic }\end{array}$ & $\begin{array}{c}\text { Occult } \\
\text { Cirrhosi } \\
\text { s }\end{array}$ & Total \\
\hline \multirow{4}{*}{$\begin{array}{l}\text { Fibroscan } \\
\text { score }\end{array}$} & \multirow{2}{*}{$\begin{array}{l}<=1 \\
0\end{array}$} & Count & 43 & 1 & 44 \\
\hline & & $\begin{array}{l}\text { \% within } \\
\text { Fibroscan }\end{array}$ & $97.7 \%$ & $2.3 \%$ & $100 \%$ \\
\hline & \multirow[t]{2}{*}{$>10$} & Count & 8 & 8 & 16 \\
\hline & & $\begin{array}{l}\text { \% within } \\
\text { Fibroscan }\end{array}$ & $50 \%$ & $50 \%$ & $100 \%$ \\
\hline \multirow{4}{*}{$\begin{array}{l}\text { Fibroscan } \\
\text { score }\end{array}$} & \multirow{2}{*}{$\begin{array}{l}<=1 \\
3\end{array}$} & Count & 47 & 3 & 50 \\
\hline & & $\begin{array}{l}\text { \% within } \\
\text { Fibroscan }\end{array}$ & $94 \%$ & $6 \%$ & $100 \%$ \\
\hline & \multirow[t]{2}{*}{$>13$} & Count & 4 & 6 & 10 \\
\hline & & $\begin{array}{l}\text { \% within } \\
\text { Fibroscan }\end{array}$ & $40 \%$ & $60 \%$ & $100 \%$ \\
\hline \multirow{2}{*}{\multicolumn{2}{|c|}{ Total }} & Count & 51 & 9 & 60 \\
\hline & & $\begin{array}{l}\text { \% within } \\
\text { Fibroscan }\end{array}$ & $85 \%$ & $15 \%$ & $100 \%$ \\
\hline
\end{tabular}




\section{DISCUSSION}

Our study included 60 chronic liver disease patients recruited from NHTMRI outpatient clinics to assess prevalence of occult cirrhosis among patients who have not any clinical or definite sonographic signs of liver cirrhosis, the study was divided into two groups: 1) Occult cirrhosis, defined as TE $\geq 13 \mathrm{kPa}$ and $\mathrm{F} 4$ on METAVIR scoring system. 2) noncirrhotic CLD $(\mathrm{TE}<13 \mathrm{kPa})$. We found that the prevalence of $\mathrm{OC}$ is considerable, representing $15 \%$ of all CLD patients. This proportion suggests up to 1 in 7 individuals with CLD may have their OC missed.

Compared to another study by Tianyan et al. (2015) done on 871 chronic Liver disease patients, the prevalence of OC is representing $12 \%$ of all CLD patients. This suggests up to 1 in 9 individuals with CLD seen may have their OC missed.

In our study among the occult cirrhosis group there were 5 male patients $(55 \%)$ and 4 females (45\%) with their age ranged between 33-55 years with the mean age 44 years and among the noncirrhotic group there were 32 male patients $(62.7 \%)$ and 19 female patients $(37.3 \%)$ their age ranged between $19-58$ years with the mean age 38.5 years.

Compared to other study done by Shiha et al. (2014) on 519 patients there was also a higher incidence in males: 411 patients $(79.2 \%)$ with the mean age 36.94 years.

Compared to other study done by Tianyan et al. (2015), among the occult cirrhosis group there were 66 male patients $(65.5 \%)$ and 35 female patients (34.5) with mean age 51 years and among the non-cirrhotic group there were 352 male patients $(59 \%)$ and 249 female patients $(41 \%)$ with mean age 49 years.
Compared to other study done by Fathy (2016) there were 19 males $(63.3 \%)$ and 11 females $(36.7 \%)$ with their age ranged between 21-59 years with the mean age 45.67.

Concerning the BMI in our study, among the occult cirrhosis group BMI was ranging from 25 to 33.7 (29.3) and among non-cirrhotic group the BMI was ranging from 18.9 to 35.2 (27.05).

Compared to other study done by Tianyan et al. (2015), among the occult cirrhosis group BMI was ranging from 23 to 30 (25.9) and among the non-cirrhotic group BMI was ranging from 22.5 to 27.7 (25).

Concerning the etiology of the chronic liver disease in our study, among the occult cirrhosis group there were 8 patients diagnosed as $\mathrm{HCV}$ positive representing $(89 \%)$ and one patient diagnosed as HBV positive representing $(11 \%)$ and among the non-cirrhotic group there were 42 patients diagnosed as $\mathrm{HCV}$ positive representing (82\%) and 4 patients diagnosed as HBV positive representing $(8 \%)$ and 5 patients diagnosed as NAFLD representing (10\%).

Compared to other study done by Tianyan et al. (2015), among the occult cirrhosis group there were 35 patients diagnosed as HCV positive representing (34\%) and 7 patient diagnosed as HBV positive representing (7\%) and 6 patients diagnosed as alcoholic liver disease representing $(6 \%)$ and 24 patients diagnosed as NAFLD representing (24\%) and 20 patients diagnosed as $\mathrm{HCV}$ or HBV with HIV positive representing (20\%) and 9 patients having other liver disease etiology representing $(9 \%)$ and among the non-cirrhotic group there were 163 patients diagnosed as HCV positive representing (27\%) and 195 patients diagnosed as HBV positive representing 


\section{ROLE OF ULTRASOUND AND TRANSIENT ELASTOGRAPHY ...}

(33\%) and 10 patients diagnosed as alcoholic liver disease representing (2\%) and 139 patients diagnosed as NAFLD representing $(23 \%)$ and 38 patients diagnosed as $\mathrm{HCV}$ or $\mathrm{HBV}$ with HIV positive representing $(6 \%)$ and 56 patients having other liver disease etiologies representing $(9 \%)$.

Concerning the laboratory investigations done in our study, among the occult cirrhosis group: total bilirubin was ranging from 0.5 to $1.9 \mathrm{mg} / \mathrm{dl}(1.2$ $\mathrm{mg} / \mathrm{dl}$ ), AST level was ranging from 25 to $180 \mathrm{U} / \mathrm{L}$ (102.5 U/L), ALT level was ranging from 18 to $231 \mathrm{U} / \mathrm{L}$ (124.5 U/L), serum albumin level was ranging from 3.4 to $4.6 \mathrm{~g} / \mathrm{dl}(4 \mathrm{~g} / \mathrm{dl})$, prothrombin concentration was ranging from 65 to 96 $\%(80.5 \%)$ and INR ranging from 1 to 1.4 (1.2), mean of serum HB was ranging from 12.2 to $17.7 \mathrm{~g} / \mathrm{dl}(14.9 \mathrm{~g} / \mathrm{dl})$ and platelets was ranging from 150000 to 266000/L (208000/L), and among the non-cirrhotic group: total bilirubin was ranging from 0.3 to $1.9 \mathrm{mg} / \mathrm{dl}(1.1 \mathrm{mg} / \mathrm{dl})$, AST level was ranging from 11 to 150 U/L (80.5 U/L), ALT level was ranging from 4 to $243 \mathrm{U} / \mathrm{L}$ (123.5 U/L) ,serum albumin level was ranging from 3.2 to 5.2 $\mathrm{g} / \mathrm{dl}(4.2 \mathrm{~g} / \mathrm{dl})$, prothrombin concentration was ranging from 73 to $100 \%(86.5 \%)$ and INR ranging from 0.9 to $1.4(1.15)$, serum HB was ranging from 12.2 to 16.8 $\mathrm{g} / \mathrm{dl}(14.5 \mathrm{~g} / \mathrm{dl})$ and platelets was ranging from 150000 to $419000 / \mathrm{L}$ (284000/L).

Compared to other study done by Tianyan et al. (2015), among the occult cirrhosis group: total bilirubin was ranging from 1.1 to $1.7 \mathrm{mg} / \mathrm{dl}(1.3 \mathrm{mg} / \mathrm{dl})$, AST level was ranging from 31 to $74 \mathrm{U} / \mathrm{L}$ (48 U/L), ALT level was ranging from 37 to $88 \mathrm{U} / \mathrm{L}(53 \mathrm{U} / \mathrm{L})$,serum albumin level was ranging from 3.8 to $4.3 \mathrm{~g} / \mathrm{dl}(4.1 \mathrm{~g} / \mathrm{dl})$, INR ranging from 1 to 1 (1), platelets was ranging from 173000 to $228000 / \mathrm{L}$ (201000/L), and among the non-cirrhotic group: total bilirubin was ranging from 1 to $1.7 \mathrm{mg} / \mathrm{dl}(1.3 \mathrm{mg} / \mathrm{dl})$, AST level was ranging from 24 to $43 \mathrm{U} / \mathrm{L}$ (31 U/L), ALT level was ranging from 25 to $64 \mathrm{U} / \mathrm{L}$ (38 $\mathrm{U} / \mathrm{L}$ ) ,serum albumin level was ranging from 4 to $4.4 \mathrm{~g} / \mathrm{dl}(4.2 \mathrm{~g} / \mathrm{dl})$, INR ranging from 1 to 1 (1), platelets was ranging from 173000 to $240000 / \mathrm{L}$ (206000/L).

In other study done by Fathy (2016) the mean values of the laboratory investigations were as follows: total bilirubin $(0.76 \mathrm{mg} / \mathrm{dl} \pm 0.42 \mathrm{mg} / \mathrm{dl})$, AST level (59.73 \pm 45.87$)$, ALT level $(63.63 \pm 50.27)$, serum albumin in $\mathrm{g} / \mathrm{dl}$ $(4.17 \pm 0.46 \quad \mathrm{~g} / \mathrm{dl}), \quad$ prothrombin concentration $\quad(87.53 \% \pm 9.37 \%), \quad$ INR $(1.07 \pm 0.12)$, serum HB $(14.19 \mathrm{~g} / \mathrm{dl})$, platelets (245533.33 \pm 240684.62$)$.

Concerning the liver fibrosis biomarkers, among the occult cirrhosis group the APRI score was ranging from 0.423 to 3.041 (1.73) and FIB-4 score was ranging from 0.97 to 3.76 (2.37), and among the non-cirrhotic group the APRI score was ranging from 0.08 to 2.679 (1.38) and FIB-4 score was ranging from 0.41 to 2.78 (1.595).

Compared to other study done by Tianyan et al. (2015), among the occult cirrhosis group the APRI score was ranging from 0.4 to $1.2(0.7)$ and FIB-4 score was ranging from 1.2 to 2.6 (1.8), and among the non-cirrhotic group the APRI score was ranging from 0.3 to 0.6 (0.4) and FIB-4 score was ranging from 0.9 to $1.6(1.2)$.

Concerning the US finding of the liver, among the occult cirrhosis group, there were 7 patients with average liver size $(78 \%)$ and 2 patients with enlarged liver size $(22 \%)$, there were 4 patients with bright echotexture $(45 \%)$ and 5 patients with coarse echotexture (55\%), and among the non-cirrhotic group there were 20 patients with average liver size (39\%) and 31 patients with enlarged liver size $(61 \%)$, there were 30 patients with 
bright echotexture $(59 \%)$ and 21 patients with coarse echotexture (41\%).

Compared to other study El-Sayed (2012) done at NHTMRI there were 33 patients $(66 \%)$ with average liver size while 17 patients $(34 \%)$ were enlarged liver size and there were 46 patients $(92 \%)$ with regular surface while 4 patients $(8 \%)$ with irregular surface and there were 10 patients $(20 \%)$ with homogenous echotexture while 30 patients $(60 \%)$ with bright echotexture and 10 patients $(20 \%)$ with coarse echotexture.

In other study Fathy (2016) there were 17 patients $(57 \%)$ with average liver size while 13 patients $(43 \%)$ were enlarged liver size and there were 28 patients $(93 \%)$ with regular surface while 2 patients $(7 \%)$ with irregular surface and there were 12 patients $(40 \%)$ with homogenous echotexture while 18 patients (60\%) with coarse echotexture.

Concerning the fibroscan score, among the occult cirrhosis group, the fibroscan score ranging from 7.8 to 23.8 Kpa (15.8 Kpa) and among the noncirrhotic group the fibroscan score was ranging from 3.2 to $15.7 \mathrm{Kpa}(9.45 \mathrm{Kpa})$.

Compared to other study done by Tianyan et al. (2015), among the occult cirrhosis group the fibroscan score ranging from 15 to $21.8 \mathrm{Kpa}(17.5 \mathrm{Kpa})$ and among the non-cirrhotic group the fibroscan score was ranging from 4.5 to 7.6 Kpa (5.7 Kpa).

Comparing the fibroscan with liver size detected by US: In fibroscan score F0 there were 12 patients $(70 \%)$ average size and 5 patients $(29.5 \%)$ enlarged size, F1 there were 2 patients $(70 \%)$ average size and 5 patients $(29.5 \%)$ enlarged size, F2 there were 4 patients (45\%) average size and 5 patients $(55 \%)$ enlarged size, F3 there were 4 patients (57\%) average size and 3 patients $(43 \%)$ enlarged size, F4 there was 1 patient (10\%) average size and 9 patients (90\%) enlarged size.

Comparing the fibroscan with liver echotexture detected by US: In fibroscan score F0 there were 13 patients $(76.5 \%)$ bright echotexture and 4 patients $(23.5 \%)$ coarse echotexture, F1 there were 11 patients $(65 \%)$ bright echotexture and 6 patients $(35 \%)$ coarse echotexture, F2 there were 3 patients $(33.3 \%)$ bright echotexture and 6 patients $(66.6 \%)$ coarse echotexture, F3 there were 3 patients (43\%) bright echotexture and 4 patients (57\%) coarse echotexture, F4 there were 4 patients $(40 \%)$ bright echotexture and 6 patients $(60 \%)$ coarse echotexture.

Other studies that targeted the noninvasive assessment of liver fibrosis as Ziol et al. (2010) who conducted their study on HCV patients postulated that the liver stiffness measurements and fibrosis stages by METAVIR scoring system correlated well, with increasing reliability in more extensive fibrosis $(F \geq 3)$. Similarly Gomez et al. (2010) concluded that fibroscan is accurate in predicting significant fibrosis which agreed with Kettaneh et al. (2010) where liver stiffness was significantly correlated with liver fibrosis stages evaluated by METAVIR scoring system.

In our study we used Fibroscan to diagnose occult cirrhosis since it is an accurate and patient friendly non-invasive tool to assess liver cirrhosis. A previous meta-analysis done by Friedrich-Rust et al. (2008) found that TE has a mean AUC of 0.94 for the diagnosis of cirrhosis using a cut-off value of $13 \mathrm{kPa}$. The AUC of this optimal diagnostic cut-off value was not significantly influenced by underlying etiologies of CLD. While we found in our study in order to detect occult cirrhosis, we have to lower the using cut-off value to $10 \mathrm{Kpa}$ to increase sensitivity of the fibroscan as it rises from $66.7 \%$ to $88.9 \%$. 
We found that both APRI and FIB-4 values were higher in the occult cirrhosis group as compared to the non-cirrhotic group. This finding is interesting given that one of the exclusion criteria for definition of occult cirrhosis was the absence of thrombocytopenia, and platelets is used to compute both APRI and FIB-4. Higher APRI was also independently associated with occult cirrhosis at baseline, reflecting the correlation between $\mathrm{TE}$ and simple biomarkers. It could be argued that simple biomarkers could be a practical solution to screening in settings of limited resources. However, APRI and FIB-4 indicated cirrhosis or advanced fibrosis only in a minority of patients with occult cirrhosis, suggesting that they have a limited diagnostic accuracy for identification of occult.

\section{CONCLUSION}

In conclusion, this study suggests that occult cirrhosis is a frequent finding. Clinicians should be aware that the absence of definite sonographic signs cannot rule out the possibility of compensated cirrhosis in its preclinical stage. Patients with occult cirrhosis can exhibit rapid development of HCC, variceal bleeding, and ascites. Those patients are also likely to be underdiagnosed and consequently under monitored if clinicians base their diagnosis exclusively on physical and sonographic signs. This can in turn translate into delayed diagnosis of complications. The implementation of screening strategies of CLD patients with TE may help the early identification of the otherwise clinically occult and unrecognized stage of compensated cirrhosis. It can prompt clinicians to initiate a program of surveillance for HCC and portal hypertension. Patients with OC due to hepatitis $\mathrm{C}$ could be given priority for antiviral therapy. These strategies may potentially reduce the burden of liver complications in patients with cirrhosis.

\section{REFERENCES}

Castera L (2012): Noninvasive methods to assess liver disease in patients with hepatitis B or C. Gastroenterology, 142:1293-1302.

D'Amico G, Garcia-Tsao $G$ and Pagliaro L (2014): Natural history and prognostic indicators of survival in cirrhosis: a systematic review of 118 studies. J Hepatol., 44:217-231.

De Franchis R. (2010): Revising consensus in portal hypertension: report of the Baveno $\mathrm{V}$ consensus workshop on methodology of diagnosis and therapy in portal hypertension. J Hepatol., 53:762768.

Degos F, Perez P, Roche B, Mahmoudi A, Asselineau $J$ and Voitot H. (2010): Diagnostic accuracy of FibroScan and comparison to liver fibrosis biomarkers in chronic viral hepatitis: a multicenter prospective study (the FIBROSTIC study). Journal of Hepatology, 53:10131021.

Durand F and Valla D (2010): Assessment of prognosis of cirrhosis. Semin Liver Dis., 28:110-122.

El-Sayed MTE (2012): Role of Transient Elastography (Fibroscan) in Assessment of Liver Fibrosis in Chronic Hepatitis C Patients. Acta Tropica., 176 (2017): 283287.

Fathy AMA (2016): Assessment of Liver Fibrosis by Transient Elastography (Fibroscan) in Chronic Hepatitis C Patients. Caspian J Intern Med., 7(4): 242-252.

Garcia-Tsao G, Friedman S, Iredale J and Pinzani M. (2010): Now there are many (stages) where before there was one: In search of a pathophysiological classification of cirrhosis. Hepatology, 51:1445-1449. 
Gerstenmaier JF and Gibson RN (2014): Ultrasound in chronic liver disease. Insights Imaging, 5:441-455.

Gomez MR, del Campo MRM, Otero MA, Vallejo $M$, Corpas $R$ and Castellano-Megias VM. (2010):

Comparative study of two models that use biochemical parameters for the noninvasive diagnosis of fibrosis in patients with hepatitis C. Med Clin., 124(20): 761-4

Kettaneh A, Marcellin P, Douvin C, Poupon R, Ziol $M$ and Beaugrand $M$. (2010): Features associated with success rate and performance of FibroScan measurements for the diagnosis of cirrhosis in HCV patients: a prospective study of 935 patients. Journal of Hepatology, 46(4): 628-634.

Roulot D, Costes JL, Buyck JF, Warzocha $U$, Gambier $\mathbf{N}$ and Czernichow S. (2011): Transient elastography as a screening tool for liver fibrosis and cirrhosis in a communitybased population aged over 45 years. Gut., 60:977-984.

Sebastiani G and Alberti A. (2012): How far is noninvasive assessment of liver fibrosis from replacing liver biopsy in hepatitis C? Journal of Viral Hepatitis, 19:18- 32 .

Shiha G, Seif S, Maher M, Etreby S, Samir W and Zalata K. (2014): Comparison between transient elastography (Fibroscan) and liver biopsy for the diagnosis of hepatic fibrosis in chronic hepatitis $\mathrm{C}$ genotype 4. Egyptian Liver Journal, 4(4): 106-111.

Tianyan C, Wong R, Wong P, RolletKurhajec KC, Alshaalan R, Deschenes $M$, Ghali $P$ and Sebastiani $G$ (2015): Occult cirrhosis diagnosed by transient elastography is a frequent and undermonitored clinical entity. Liver Int., 35(10):2285-93.

Vallet-Pichard A, Mallet V, Nalpas B, Verkarre $V$, Nalpas $A$ and DhalluinVenier V. (2011): FIB-4: an inexpensive and accurate marker of fibrosis in $\mathrm{HCV}$ infection. Comparison with liver biopsy and fibrotest. Hepatology, 46:32-36.

Ziol M, Handra-Luca A and Kettaneh A. (2010): Noninvasive assessment of liver fibrosis by measurement of stiffness in patients with chronic hepatitis C. Hepatology, 41: 48-54. 


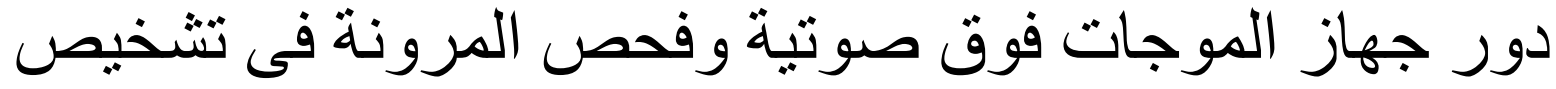 التليف الكبدى الغير واضح لأمر اض اضوفئه الكبد المزمنة

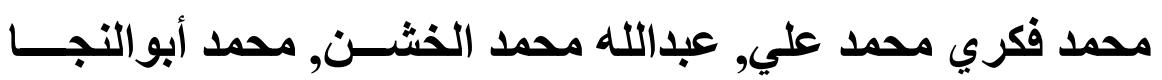 قسم الأثعة التشخيصية, كلية الطب - جامعة الأزهـر ملـر}

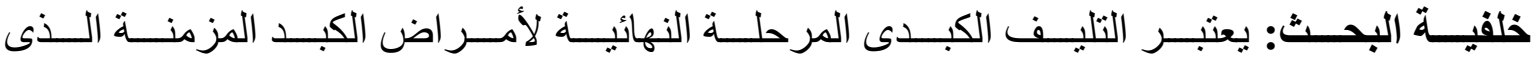

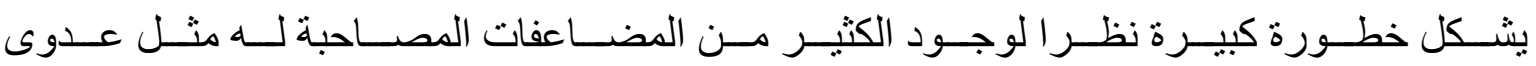

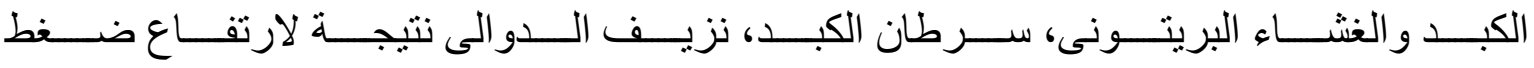

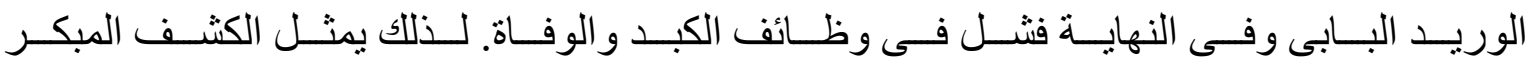

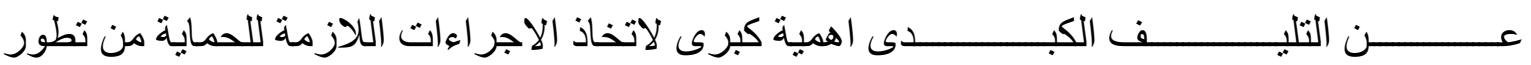
المرض و البحث الدقيق عن المضاعفات.

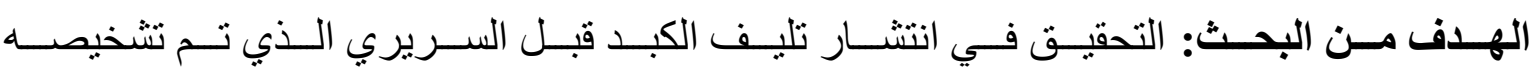

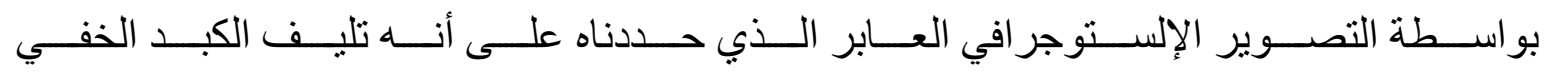

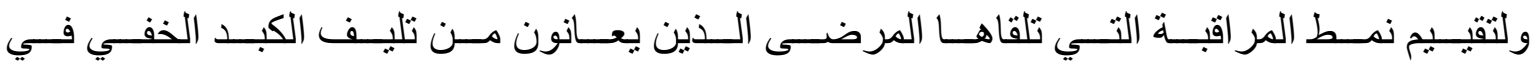
الممارسة السريرية الحالية.

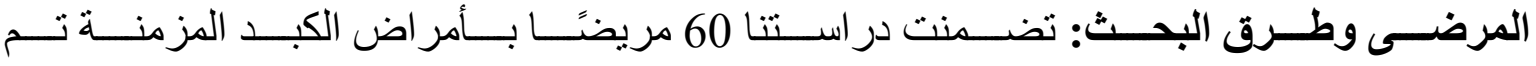

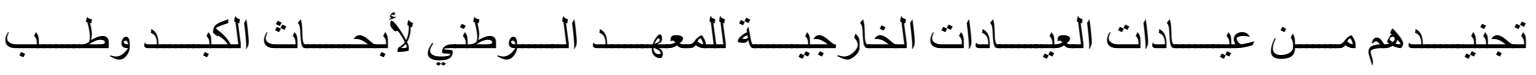

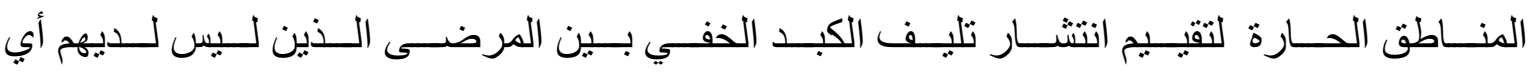

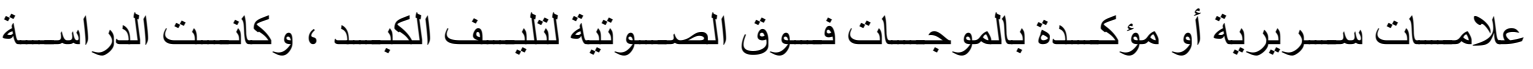

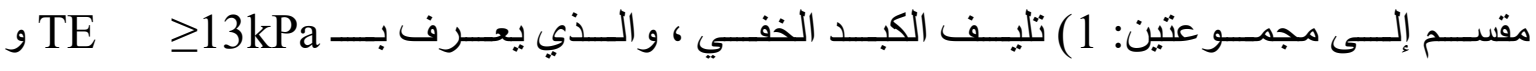

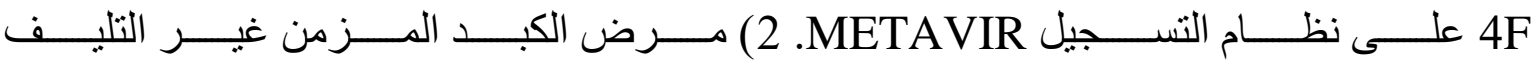

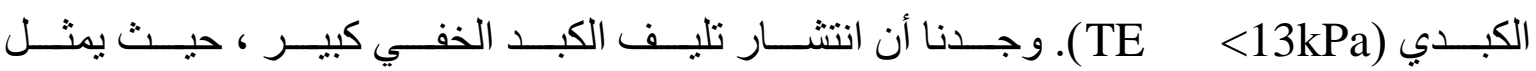

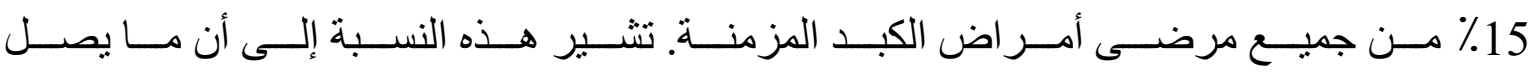

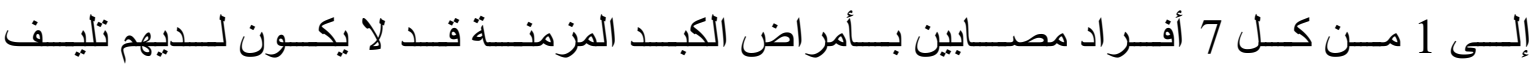
الكبد الخفي.

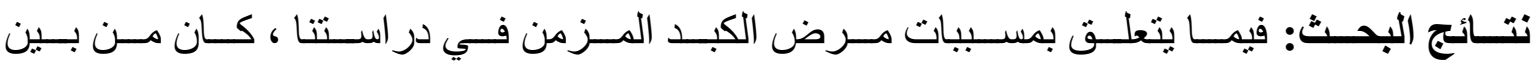

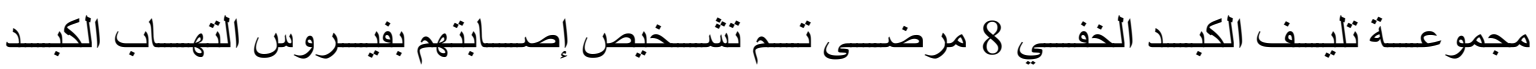




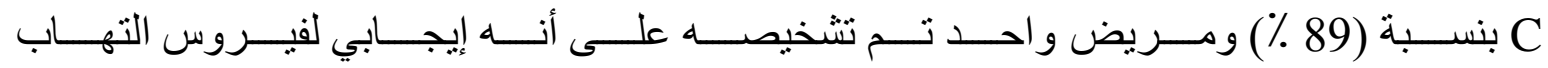

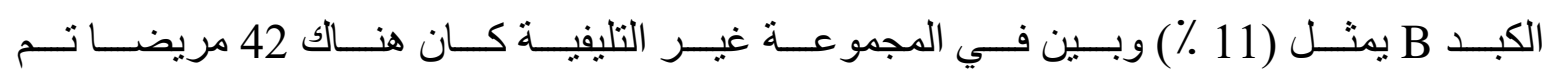

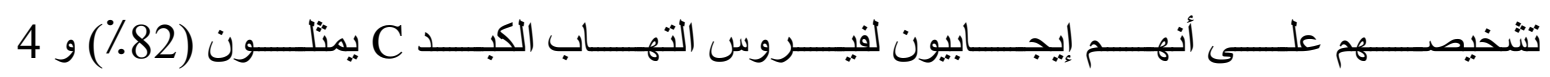

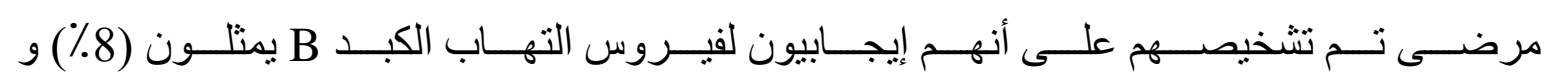

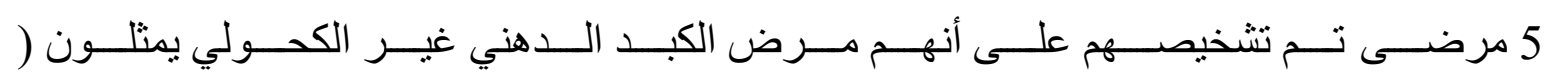

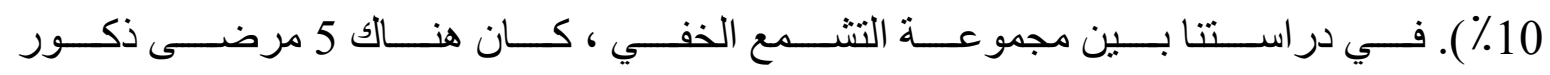

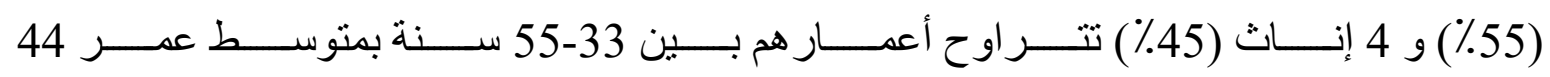

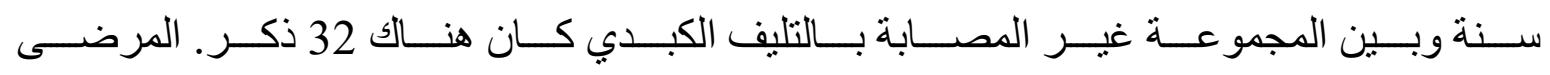

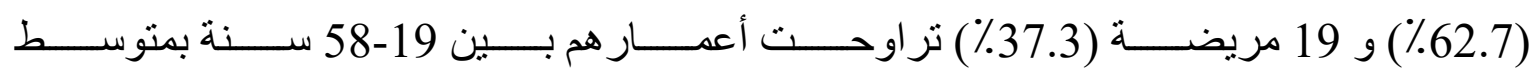
عمر 38.5 سنة.

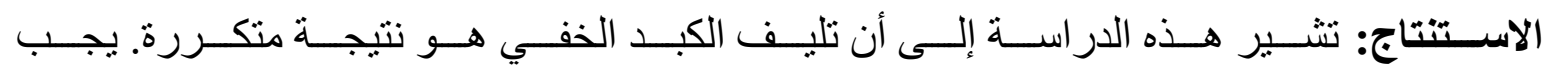

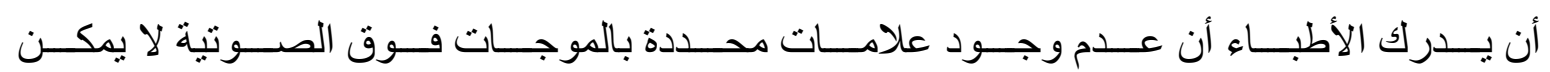

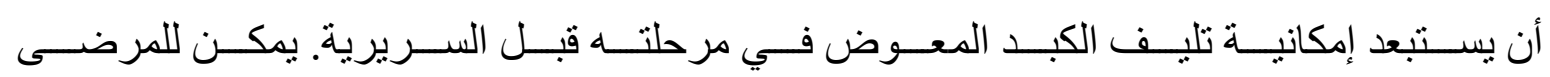

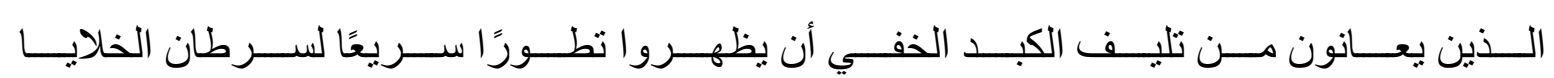
الكبدية ونزيف الدو الي والاستسقاء.

الكلمات الدالة: مرض الكبد المزمن ، تثمع الكبد الخفي ، تصوير المرونة العابر 